\title{
Cryptosporidium in Calves, Lambs and Kids at Haramaya, eastern Ethiopia
}

${ }^{1}$ *Alemayehu Regassa, ${ }^{1}$ Oda Gizaw, ${ }^{2}$ Fufa Abunna, ${ }^{1}$ Rahmeto Abebe, ${ }^{3}$ Desta Beyene, ${ }^{1,5}$ Bekele Megersa, ${ }^{1}$ Etana Debela, ${ }^{1,4}$ Kassahun Asmare and ${ }^{4}$ Eystein Skierve

${ }^{1}$ Hawassa University, School of Veterinary Medicine, P. O. Box: 05, Hawassa, Ethiopia

${ }^{2}$ Addis Ababa University, College of Veterinary Medicine and Agriculture, P.O.Box, 34, Bishoftu, Oromia, Ethiopia

${ }^{3}$ Haramaya University, College of Veterinary Medicine, P. O. Box: 138, Dire Dawa, Ethiopia

${ }^{4}$ Norwegian School of Veterinary Science, Department of Production Animal Clinical Sciences, P.O. Box 8146 Dep., NO-0033 Oslo, Norway

${ }^{5}$ Universitäte Hohenheim, Institute of Animal Production in the Tropics and Subtropics Garbensrae 17, 70599 Stuttgart, Germany

*Corresponding author: Alemayehu Regassa, Hawassa University, School of Veterinary Medicine, P. O. Box: 05, Fax $=+046225187$, Hawassa, Ethiopia, e-mail: alemregassa@yahoo.com,Cell-phone: +251-911-126227

\section{Abstract}

A cross sectional study was carried out from November 2010 to April 2011 to determine the prevalence of Cryptosporidium in calves, lambs and kids and to assess potential risk factors in Haramaya, eastern Ethiopia. Hence, fecal samples from a total of 237 study animals (133 calves, 63 lambs and 41 kids) were tested with Sheather's flotation technique and Modified Ziehl-Neelsen Staining. Accordingly, the overall prevalence was found to be $23.6 \%(56 / 237)$ with the prevalence of $27.8 \%(37 / 133)$ in calves, $22.2 \%(14 / 63)$ in lambs and $12.2 \%(5 / 41)$ in kids. The prevalence of Cryptosporidium significantly $(\mathrm{p}=0.047)$ varied with species of study animals being three times higher likelihood of occurrence in calves compared to its chance of occurrence in kids $(\mathrm{OR}=2.8,95 \% \mathrm{CI}=1.0,7.6)$. No significant difference in prevalence was observed between kids and lambs. The occurrence of the disease was also assessed among the species of animals by taking into consideration different demographic characteristic of the animals including breed, age and sex. For caprine, the prevalence was higher in the cross breed animals $(28.6 \%)$ followed by the breed of Hararge highland (25\%) with no report of the disease in Boer and Ogaden breeds. In ovine, no association was observed between the infection occurrence and the potential risk factors. Analysis of the risk factors in bovine revealed a significant ( $\mathrm{p}=$ 0.044) difference in disease occurrence among age groups with almost three times more likelihood of the disease occurrence in calves under 3 months than older age category $(\mathrm{OR}=2.9,95 \% \mathrm{CI}=1.0,8.2)$. In conclusion, this study demonstrated the importance of Cryptosporidium in young ruminants with a higher prevalence among calves than lambs and kids.

Key words: Cryptosporidium; Prevalence; Risk Factors; Calves, Lambs, Kids, Haramaya, Ethiopia 


\section{Introduction}

Cryptosporidiosis is an emerging protozoan disease, caused by Cryptosporidium species, that can cause gastrointestinal infection in a wide variety of mammals including human, cattle, sheep, goat, pig and horses worldwide (Nasir et al., 2009; Degerli et al., 2005). Beef and dairy cattle are infected with at least two distinct species namely Cryptosporidium parvum and Cryptosporidium andersoni (Olson et al., 1997), the infection being encountered after ingestion of the microscopic infective oocysts. Oocysts are discharged in the feces of infected cattle and are of primary importance for the dispersal and survival of the parasites (Bowman, 2003). Calves are primarily infected via the fecal-oral route and it takes less than 50 oocysts to infect a healthy calf (Fayer et al., 2000). Infection can rapidly spread from calf to calf when animals are communally housed and overcrowded or from cow to calf via the udders when they are contaminated with infected calf feces in the lying area of the dams (Nasir et al., 2009). These oocysts are resistant to the environment and remain infective for months in cold water or dump, cool environment (Olson et al., 1997).

Clinical cryptosporidiosis is frequently not diagnosed, yet it has been incriminated as an important cause of diarrhea in neonates (Nydam and Peregrine 2010; Goma et al., 2006). Clinically, the disease is characterized by anorexia and diarrhea, often intermittent, which may result in poor growth rate (Taylor et al., 2007; Urquhart et al., 1987). The severity of clinical disease may be associated with the animals' immune and nutritional status (Olson et al., 1997). It is also characterized by low morbidity which, however may become severe when associated with other pathogens (Prakash et al., 2009; Potter and Esbroeck, 2010). According to Nasir et al., (2009), although calves 1-3 weeks old seem to be most susceptible, cryptosporidium species has also been found in cattle over two years of age impairing rate of gain in feedlot cattle and milk production in dairy cattle (Olson et al., 1997). A variety of methods is available for detection of Cryptosporidium species including microscopic, immunological and molecular techniques. Microscopic detection is based on finding the environmental and chemical resistant oocysts in fecal samples (Potters and Esbroeck 2010). Oocysts may be demonstrated using Ziehl-Nielsen stained fecal smears in which the sporozoites appear as bright red granules (Taylor et al., 2007).

In Ethiopia, there is limited information on the status of Cryptosporidiosis except the work conducted by Rahmeto Abebe et al. (2008) on the epidemiological study of Cryptosporidium infection in dairy calves and by Dinka Ayana et al., 
(2009) on the Eimeria and Cryptosporidium infections in sheep and goats in central Ethiopia. Therefore, this paper reports the prevalence of Cryptosporidia and associated risk factors in the occurrence of the infection in calves, lambs and kids in Haramaya farms, Eastern Ethiopia.

\section{Materials and Methods}

Study area

The study was conducted in Haramaya University farms, Eastern Ethiopia. Selection of the farms was purposive because of the availability of the study animals (Calves, Lambs and Kids). Haramaya University is found in Eastern Hararghe Zone of Oromia Region, Ethiopia; located at approximately $509 \mathrm{~km}$ east of Addis Ababa, geographically lies between $9^{0} 26^{\prime} \mathrm{N}$ latitude and $42^{0} 3^{\prime} \mathrm{E}$ longitude at an altitude of 2000 meter above sea level (masl). The area has a mean temperature ranging from 10 to $18{ }^{\circ} \mathrm{C}$ with relative humidity of $65 \%$. It receives an average annual rainfall of $800 \mathrm{~mm}$ with bimodal distribution of the seasonal pattern peaking in mid April and mid August of the year; however there is a variation from year to year (Data from East Hararghe Bureau of Agriculture).

\section{Study animals}

Only young animals of age group below 12 months for calves and below 6 months for lambs and kids were considered for this particular research. This was based on the previous reports that indicated higher occurrence of the disease in these age categories. Thus, totally 237 were included with the proportion of 133 $(56.12 \%)$ calves, $63(26.58 \%)$ lambs and 41 (17.30\%) kids. The association of the disease occurrence was seen in relation with different age category with classification of $\leq 3$ months, 3-6 months, $>6$ months for calves, and $\leq 1$ months, 1-3 months, $>\overline{3}$ months for lambs and kids. The other demographic characteristics (sex and breed) of the study animals were also considered during data collection and analyzed to assess the effect of these risk factors on the occurrence of the disease. Both sheep and goats were crosses of Dorper and Boar breeds, respectively which were imported by Ethiopian Sheep and Goat Productivity Improvement Program (ESGPIP). 
included in the study which was 237 (133 calves, 63 lambs, 41 kids) as these were the only animals within the required age category.

\section{Methodology}

Fecal samples were collected directly from the rectum of the study animals using disposable gloves, placed in universal bottle and transported in ice box to laboratory for processing on the same day. The samples were first screened by Sheather's Floatation Technique (Hendrix, 1998) and those found positive were retested by Modified Zeihl-Neelson Staining (Kaufmann, 1996) for confirmation. Briefly, the procedures for the two testes are described as follows:

Sheather's floatation technique: Three grams of feces were weighted from each animal and mixed with $10 \mathrm{ml}$ of sugar solution. Then it was poured through tea strainer into a beaker and then the solution was added into $12 \mathrm{ml}$ centrifuge tube and placed into the centrifuge. The tube was then filled with sugar solution about 1 inch from the top of the tube without putting cover slip on the tube and centrifuged at 1200rpm for 5 minutes. Then the test tube was removed from the centrifuge and filled to the top with sugar solution and then covered with cover slip on the tube and kept at standing for 10 minutes. Finally, the cover slip was removed from the tube and was placed on slide labeled with the animal name or number. The entire cover slip was examined at $40 \mathrm{X}$ to identify oocysts and results were recorded (Trotz-Williams et al., 2005).

Modified Zeihl-Neelson staining: Thin fecal smears were air dried and passed quickly through a flame. The smears were stained with Ziehl-Neelson's Carbol fuchsin solution for 2 minutes and then rinsed with tap water. The smears were rinsed for a few seconds with acid alcohol (3\% hydrochloric acid in 70\% ethanol). Again the smears were rinsed with tap water. The smears were counterstained with brilliant Green $(0.5 \%)$ for 2 minutes and rinsed again with tap water. The slides were air dried and examined microscopically at $100 \mathrm{x}$ objective using oil immersion. Cryptosporidium oocysts appeared bright red granules on a blue background (Kaufmann, 1996). Only those which were positive on modified Zeihl-Neelson technique were recognized as positive and others were registered as negative.

Data management and analysis

Data were recorded in Microsoft excel spread sheet for statistical analysis. 
Descriptive statistics was used to summarize the data and calculate same of the sample statistics and various proportions. Additionally, inferential statistics were employed to understand certain population parameters. Logistic regression analysis was used to see the presence, direction and strength of association of the potential risk factors with occurrence of Cryptosporidium infection using statistical soft ware (STATA 11).

\section{Results}

Prevalence

Of 237 animals examined using Zeihl-Neelsen staining technique, the overall prevalence of Cryptosporidium in all species was found to be $23.6 \%$. The prevalence in calves was $27.8 \%(37 / 133)$ while the proportion in lambs and kids were $22.2 \%(14 / 63)$ and $12.2 \%(5 / 41)$, respectively (Table 1$)$.

Table 1: The result of flotation technique and Zeihl -Neelsen staining techniques for the diagnosis of Cryptosporidium

\begin{tabular}{lccccc}
\hline \multirow{2}{*}{$\begin{array}{l}\text { Species } \\
\text { of }\end{array}$} & Number & \multicolumn{2}{c}{ Flotation Technique } & \multicolumn{2}{c}{ Zeihl-Neelsen Technique } \\
\cline { 3 - 6 } $\begin{array}{l}\text { study } \\
\text { animals }\end{array}$ & examined & $\begin{array}{c}\text { Number } \\
\text { positive }\end{array}$ & $\begin{array}{c}\text { \% positive } \\
(95 \% \text { CI })\end{array}$ & $\begin{array}{c}\text { Number } \\
\text { positive }\end{array}$ & $\begin{array}{c}\text { \% positive } \\
(95 \% \mathrm{CI})\end{array}$ \\
\hline Kids & 41 & 16 & $39.0(24.6,55.4)$ & 5 & $12.2(4.6,27.0)$ \\
Lambs & 63 & 21 & $33.3(22.0,46.1)$ & 14 & $22.2(13.1,34.8)$ \\
Calves & 133 & 47 & $35.3(27.5,44.3)$ & 37 & $27.8(20.6,36.4)$ \\
Total & 237 & 84 & $35.4(29.4,41.9)$ & 56 & $23.6(18.5,29.6)$ \\
\hline
\end{tabular}

Result of risk factor analysis

The occurrence of Cryptosporidium among the three species of study animals was compared using logistic regression analysis and a significant $(\mathrm{P}=0.047)$ difference of the disease occurrence was observed among calves, lambs and kids. Hence, the likelihood of its occurrence in calves was about three times more than the chance of its occurrence in the kids $(\mathrm{OR}=2.8,95 \% \mathrm{CI}=1.0,7.6)$ whereas no significant difference was observed between kids and lambs (Table 2 and 3 ). 
Table 2: Logistic regression analysis of species level occurrence of Cryptosporidium

\begin{tabular}{lllll}
\hline $\begin{array}{l}\text { Species of study } \\
\text { animals }\end{array}$ & No tested & No $(\%)$ positive & OR $(95 \%$ CI $)$ & P-value \\
\hline Kids & 41 & $5(12.2)$ & 1 & \\
Lambs & 63 & $14(22.2)$ & $2.1(0.7,6.2)$ & 0.202 \\
Calves & 133 & $37(27.8)$ & $2.8(1.0,7.6)$ & 0.047 \\
\hline
\end{tabular}

Calves: Higher prevalence of Cryptosporidium was recorded among Holstein Friesian (HF) breed $(28.8 \%, 95 \% \mathrm{CI}=19.1,40.8)$ followed by Ogaden $(27.3 \%$, $95 \% \mathrm{CI}=15.5,43.1)$ and then Crosses $(25.0 \%, 95 \% \mathrm{CI}=8.3,52.6)$. The multivariable logistic regression analysis of the risk factors revealed that the occurrence of Cryptosporidium significantly $(\mathrm{p}=0.044)$ varied with age group indicating three times higher likelihood $(\mathrm{OR}=2.9,95 \% \mathrm{CI}=1.0,8.2)$ among calves under three months compared to the older ones (Table 2). There was no significant difference observed in the disease occurrence among breeds and the sex.

Lambs: Higher prevalence was recorded in crosses $(40 \%, 6 / 28)$ followed by black head ogaden (21.4\%) and Hararghe highland (16\%) though statistically significant difference was not observed. The highest infection was observed among the lambs between the age $\leq 1$ month (40\%) followed by $1-3$ months $(26.1 \%)$ and $>3$ months $(13.3 \%)$. However, the difference was not statistically significant $(\mathrm{P}=0.062)$. Similarly, prevalence among the male $(29.4 \%)$ was higher than females (13.8\%).

Kids: There was no significant difference among the four breeds of goats with the highest report in the crosses $(28.6 \%)$ followed by breed of the Hararge highland $(25 \%)$. Cryptosporidium oocyst identified in the faeces of Boer and Ogaden breeds. 
Table 3: The multivariable logistic regression analysis of the different likely risk factors considered for Cryptosporidium occurrence in the study area $(\mathrm{n}=237)$ ${ }^{a}$ As all the Boer and Ogaden breeds of goats were negative, Odds Ratio and its Confidence Interval could not be calculated, rather chi-square was employed for comparison between the rest of the two breeds (breeds of cross and Hararghe high lands) $\left(x^{2}=0.62, \mathrm{p}\right.$-value $\left.=0.891\right)$.

\begin{tabular}{|c|c|c|c|c|c|}
\hline \multicolumn{2}{|c|}{ Risk factors } & № tested & № (\%) positive & OR ( $95 \% \mathrm{CI})$ & P-value \\
\hline \multicolumn{6}{|l|}{ Bovine } \\
\hline \multirow[t]{3}{*}{ Breed } & Cross & 16 & $4(25.0)$ & 1 & \\
\hline & HF & 73 & $21(28.8)$ & $1.2(0.3,4.1)$ & 0.825 \\
\hline & Ogaden & 44 & $12(27.3)$ & $1.0(0.3,4.0)$ & 0.955 \\
\hline \multirow{3}{*}{ Age } & $>6$ months & 36 & $6(16.7)$ & 1 & \\
\hline & 3-6months & 35 & $9(25.7)$ & $1.6(0.6,4.1)$ & 0.299 \\
\hline & $<3$ months & 62 & $22(35.5)$ & $2.9(1.1,8.2)$ & 0.044 \\
\hline \multirow{2}{*}{ Sex } & Female & 63 & $17(27.0)$ & 1 & \\
\hline & Male & 70 & $20(28.6)$ & $1.2(0.6,2.7)$ & 0.621 \\
\hline \multicolumn{6}{|l|}{ Ovine } \\
\hline \multirow[t]{3}{*}{ Breed } & BHS & 28 & $6(21.4)$ & 1 & \\
\hline & Cross & 10 & $4(40.0)$ & $3.8(0.6,22.4)$ & 0.142 \\
\hline & $\mathrm{HH}$ & 25 & $4(16.0)$ & $1.4(0.3,6.1)$ & 0.671 \\
\hline \multirow[t]{3}{*}{ Age } & $>3$ months & 30 & $4(13.3)$ & 1 & \\
\hline & 1-3months & 23 & $6(26.1)$ & $2.1(0.4,11.0)$ & 0.382 \\
\hline & $\leq 1$ months & 10 & $4(40.0)$ & $5.8(1.0,36.5)$ & 0.062 \\
\hline \multirow[t]{2}{*}{ Sex } & Female & 29 & $4(13.8)$ & 1 & \\
\hline & Male & 34 & $10(29.4)$ & $2.0(0.5,7.8)$ & 0.338 \\
\hline \multirow{5}{*}{$\begin{array}{l}\text { Caprine } \\
\text { Breed }\end{array}$} & & & & & \\
\hline & Boer & 8 & $0(0.0)$ & & \\
\hline & Cross & 7 & $2(28.6)$ & & \\
\hline & Hararghe & 12 & $3(25.0)$ & $x^{2}=0.62$ & $0.891^{\mathrm{a}}$ \\
\hline & Ogaden & 14 & $0(0.0)$ & & \\
\hline \multirow{3}{*}{ Age } & $<1$ months & 11 & $1(9.1)$ & 1 & \\
\hline & 1-3months & 20 & $3(15.0)$ & $1.9(0.1,35.0)$ & 0.665 \\
\hline & $>3$ months & 10 & $1(10.0)$ & $1.2(0.2,2.7)$ & 0.940 \\
\hline \multirow[t]{2}{*}{ Sex } & Female & 21 & $4(19.1)$ & 1 & \\
\hline & Male & 20 & $1(5.0)$ & $4.8(0.4,61.0)$ & 0.231 \\
\hline
\end{tabular}


The higher prevalence $(27.8 \%)$ of Cryptosporidium in calves than in lambs $(22.2 \%)$ and kids $(12.2 \%)$ is in line with reports of Fayer and Xiao et al. (2004) and Wang et al. (2010) who explained calves have attracted extensive attention as they are widely infected with Cryptosporidium. The higher prevalence in calves might be due to relatively intensive calves management system or overcrowded housing system of these animals when compared to kids and lambs, and this can result in relatively low immunity of calves. Casemore et al. (1985) reported, even though Cryptosporidium revealed in lambs and kids, it is more common in calves. The study conducted by Dinka Ayana et al. (2009) on Eimeria and Cryptosporidium infections in sheep and goats at ELFORA export abattoir, Central Ethiopia exceptionally reported zero prevalence of Cryptosporidium. In the current study, there is difference in the production system between the study animals, in that calves were kept under intensive management system with confined indoor housing whereas lambs and kids were grazing outside with their dams. Moreover, lambs and kids have relatively adequate space at night which may be attributed to the relatively lower occurrence of the disease in the two species.

Higher stocking rate enhances the infection since infected calves produce large numbers of oocyts into confined calf house ensuring a high environmental contamination (Geurden et al., 2006). In contrast, in the extensively reared and traditional husbandry system, calves remain in large outdoor paddocks or with dam on pasture, where oocysts are dispersed on a large surface and are exposed to direct sunlight, which reduces the oocysts viability, resulting in a reduced infection pressure (Lefay et al., 2000). The infection in sheep and goats is also common and severity of clinical symptoms varies, the infection often causes death of lambs and kids (Majewska et al., 2000). Walker et al. (2001) also mentioned that in the extensively reared and traditional husbandry system, animals remain at large outdo or paddocks or with dam on pasture, where oocysts are dispersed on a large surface and are exposed to direct sunlight, which reduces the oocysts viability, resulting in a reduced infection pressure.

The $27.8 \%$ prevalence of Cryptosporidium in calves in the current study was comparable to some of the previous works. Lower prevalences of $19.2 \%$ in Zambia (Geurden et al., 2006), 17.9\% in France (Lefay et al., 2000), 17.6\% in central Ethiopia (Rahmeto Abebe et al., 2008) and 11.9 in USA (Fayer et al., 2008) were reported. On the other hand, there were relatively higher prevalence reports of Cryptosporidium in different countries. Prevalence of $35.5 \%$ in USA, 
$33.5 \%$ in Vietnam, 27.9\% in UK, $28.5 \%$ in Sirlanka and 47.9 in Spain by Santin et al. (2004), Nguyen et al. (2007), Brook et al. (2008), Noordin et al. (2000) and Castro-Hermida et al. (2002) were reported, respectively. Exceptionally, some of the reports revealed the highest prevalence of 50\% in Netherlands (Huetink et al., 2001) and 70\% in USA (Fayer et al., 2000). These differences in the prevalence among countries may be attributed to the difference in the stocking rate and husbandry system of livestock production system of the countries. Besides, these variations could also be due to the difference in the susceptibility of the target population that related to age difference. Furthermore, the discrepancy between the sensitivity of the diagnostic tests utilized might also the cause of this variation (Geurden et al.,2006).

According to Huetink et al. (2001); Xiao et al. (2004) and Nguyen et al. (2007), age appeared to be an important factor that influences the occurrence of the Cryptosporidium. Our finding in the current study is in agreement with the above finding that calves under 3 months are at higher risk of infection compared to the older ones $(\mathrm{OR}=2.8)$. The higher prevalence in this age group can be attributed to the fact that these age groups are highly susceptible to the disease because of the immature immune system of the animal at this age. Kvac et al., (2006) explained that the animal is becoming resistant with age due to the immune development through time. For instance, Brook et al. (2008) recorded that calves under 4 months were 13 times more likely to be infected with Cryptosporidium than older ones. It was also agreed by Xiao et al., (2004) and Nguyen et al. (2007) that although Cryptosporidium was observed among all age groups, the prevalence of the disease in calves less than 6 months is significantly higher than older cattle. Additionally, some of the Synergic infection of enteropathogens, such as Rota virus, Corona virus, Salmonella and E. coli can result in the immunecompromised condition and the newborn animal will be more susceptible to the Cryptosporidium infection (Lefay et al., 2000). Furthermore, in our current study it was observed that less attention was given to the newborn animals with inadequate place for calves, poor feeding systems, water and/or milk in containers in which they may defecate, dropping feeds in the pen.

The absence of significant association between the infection status and age in lambs of this study may be due to small number of lambs. The same reasoning was forwarded by Castro-Hermida et al., (2002) that the prevalence of Cryptosporidiosis can be underestimated because of the low number of samples. However, in the current study lambs of 1 month and below are about six times more susceptible $(\mathrm{OR}=5.8,95 \% \mathrm{CI}=1.0,36.5)$ than older lambs though this 
difference was not statistically $(p=0.062)$ appreciated. That is to say, the highest proportion of the infection was encountered among the lambs of age $\leq 1$ month (40\%) followed by $1-3$ months $(26.09 \%)$ and $>3$ months $(13.33 \%)$. Similarly, Majewska et al., (2000) reported that symptomatic Cryptosporidiosis has been reported mainly in lambs below 1 month of age. Regarding the age distribution of Cryptosporidiosis in lambs, Causapé et al., (2002) stated that lambs shedding oocysts peaked at 8-14 days of age (76.2\%) and they also added that infection was significantly higher in lambs aged between 1 and 21 days $(66.4 \%)$ than in those of 22-90 days of age. The slightly higher percentage of lambs shedding oocysts in the first month of age $(40 \%)$ in this study indicated that most of them are infected immediately after birth. This observation is consistent with the duration of the parasite's life cycle which is around 4 days and suggested heavy environmental contamination in the lambing area or infection from post parturient dams since lambs remain with them permanently and may easily get infected at suckling. This peak early infection rate is in agreement with results of Causape et al., (2002) indicating that infection is most frequent during the first 2 weeks of life and the proportion of infected animals decreases thereafter.

The current study also revealed that the prevalence of Cryptosporidium in kids has no association $(\mathrm{P}>0.05)$ with breed, age and sex of the goats and which is in line with some of the earlier reports. For instance, Bejan et al., (2009) reported the absence of significant linear correlation between oocysts elimination and the age of the goat kids. Misic et al., (2006) and Bejan et al., (2007), although they recorded the highest prevalence and intensity of the infection between 1 and 2 weeks of age, there was no significant difference between the elimination of the oocysts in kids and age which translates into detection of Cryptosporidium infection in goats of all age groups. Bejan et al., (2009) also argued the absence of sex effect on elimination of Cryptosporidium oocysts in goat kids. Similarly, Nooredeen et al., (2000) concluded that there is no correlation between Cryptosporidium infection and sex of the animals. In contrary to this, other studies (De Graaf et al., 1999; Bomfim et al., 2005; Diaz et al., 2010) reported the existence of association between the Cryptosporidium infection and age of the animals.

In conclusion, this study revealed the occurrence of cryptosporidium in calves, kids and lambs with higher prevalence in calves than in lambs and kids. Concerning the risk factors, higher occurrence was observed among calves less than 3 months of age when compared with other age categories. Hence, it was. 
observed among calves less than 3 months of age when compared with other age categories. Hence, it was observed that species and age were the most important risk factors associated with the occurrence of the infection and this result can potentially contribute to increased understanding of the scientific community in this regard.

\section{Acknowledgements}

Workers at Haromaya University Farms and College of Veterinary Medicine laboratory staffs are highly appreciated for their cooperation during the field work and the laboratory activities.

\section{References}

Bejan, A., Mircean, V., Radu, C., Smaro. S., Cozma V., 2009. Epidemiology of Cryptosporidium spp. infection in goat kids in the central and the northwest part of Romania. Sc. Parasit., 1, 32-36.

Bejan, A., Titilincu, A., Sarbu, R., Cozma, V. 2007. Cercetări privind epidemiologia şi diagnosticul criptosporidiozei la iezi; Revista Scientia Parasitologica, 2, 31-38.

Bomfim, T.C.B., Huber, F., Gomes, R.S., Alves, L.L., 2005. Natural infection by Giardia sp. and Cryptosporidium sp. in dairy goats, associated with possible risk factors of the studied properties. Veterinary Parasitology, 134, 9-13.

Bowman, D.D., 2003. Georgis' Parasitology for Veterinarians, $8^{\text {th }}$ ed. Saunders. pp. 98.

Brook, E., Hart, C.A., French, N., Christley R., 2008. Prevalence and risk factors for Cryptosporidium spp. infection in young calves. Veterinary Parasitology, 152, 4652.

Casemore, D.P., Armstrong,M., Sands, R.L., 1985. Laboratory Diagnosis of Cryptosporidiosis. J Clin Pathol., 38, 1337-1341.

Causape, A.C., Quilez, J., Sanchez-Acedo, C., Cacho, E., Lopez-Bernad, F., 2002. Prevalence and analysis of potential risk factors for Cryptosporidium parvum infection in lambs in Zaragoza (northeastern Spain). Veterinary Parasitology, 104, $287-298$.

Castro-Hermida, J. A., González-Losada, Y. A., Ares-Mazás, E. 2002. Prevalence of and risk factors involved in the spread of neonatal bovine cryptosporidiosis in Galicia (NW Spain). Veterinary Parasitology, 106, 1-10. 
De Graaf, D.C., Vanopdenbosch, E., Ortega-Mora, L.M., Abbassi, H., Peeters, J.E., 1999. A review of the importance of cryptosporidiosis in farm animals. Int J Parasitol., 29(8), 1269-87.

Degerli, S., Celiksoz, A., Kalkan, K., Ozcelik, S., 2005. Prevalence of Cryptosporidium Spp. and Giardia Spp. in cows and calves in Sivas. TurkJ Vet Sci., 29, 995-999.

Diaz, P., Quilez, J., Robinson, G., Chalmers, R. M., Diez-Ba nos, P., Morrond, P., 2010. Identification of Cryptosporidium xiaoi in diarrhoeic goat kids (Capra hircus) in Spain. Veterinary Parasitology, 172, 132-134.

Fayer, R. and Xiao, L., 2008. Cryptosporidium and Cryptosporidiosis. $2^{\text {nd }}$ ed. CRC press, London, New York.

Fayer, R., Morgan, U., Upton, S.J., 2000. Epidemiology of Cryptosporidium: transmission, detection and identification. Int. J. Parasitol. 30, 1305-1322.

Geurden, T., Goma, F.Y., Siwila, J., Phiri, I.G.K., Mwanza, A.M., Gabriel, S., Claerebout, E., Vercruysse, J. 2006. Prevalence and genotyping of Cryptosporidium in three cattle husbandry systems in Zambia. Veterinary Parasitology, 138, 217-222.

Goma, F. Y., Geurden, T., Siwila, J., Phiri, I. G. K., Gabriel, S., Clearebout, E., Vercruysse, J., 2006. The prevalence and molecular characterization of Cryptosporidium Spp. in small ruminants in Zambia. Small Ruminant Research, 72, 77-80.

Hendrix, C.M., 1998. Diagnostic Veterinary Parasitology, $2^{\text {nd }}$ edition. Mosby, Inc. USA. 239-264.

Huetink, J.W.B., Van der Giessen, J.P.T.M., Noordhuizen H.W., Ploeger., 2001. Epidemiology of Cryptosporidium spp. and Giardia duodenalis on a dairy farm. Veterinary Parasitology, 102, 53-67.

Kaufmann, J., 1996. Parasitic Infections of Domestic Animals: A Diagnostic Manual. Basel, Boston, Berlin, Birkhauser, p. 23-25.

Kvac, M., Kouba, M., Vitovec, J., 2006. Age-related and housing-dependence of Cryptosporidium infection of calves from dairy and beef herds in South Bohemia, Czech Republic. Veterinary Parasitology, 137, 202-209.

Lefay, D., Naciri, M., Poirier, P., Chermette R., 2000. Prevalence of Cryptosporidium infection in calves in France. Veterinary Parasitology; 89, 1-9. 
Majewska, A. C., Werner, A., Sulima, P., Luty, T., 2000. Prevalence of Cryptosporidium in sheep and goats bred on five farms in west-central region of Poland. Veterinary Parasitology, 89, 269-275.

Misic, Z., Radivojevic, S., Katic, Kulisic, Z., 2006. Cryptosporidium infection in lambs and goat kids in Serbia, Acta Vet., (Beograd); 56, 49-54.

Nasir, A., Avais, M., Khan, M. S., Ahmad, N., 2009. Prevalence of Cryptosporidium parvum infection in Lahore (Pakistan) and its association with diarrhea in dairy calves. Int. J. Agric. Biol., 11, 221-224.

Nguyen, S. T., Nguyen, D. T., Quyet Le, D., Le Hua, L. N., Nguyen, T. V., Honma, H., Nakai Y., 2007. Prevalence and first genetic identification of Cryptosporidium spp. in cattle in central Viet Nam. Veterinary Parasitology; 150, 357-361.

Nydam, D. V. and Peregrine, A. S., 2010. Control and impact of dairy calf disease: Cryptosporidiosis. $82^{\text {nd }}$ Western Veterinary Conference, Cornel University, NY, USA. 534, 3-7.

Olson, M.E., Torlakson, C.L., Deselliers, L., Morck, D.W., McAllister, T.A., 1997. Giardia and Cryptosporidium in Canadian farm animals. Veterinary Parasitology. $68,375-380$.

Potter, L. and Esbroeck, V.M., 2010. Negative staining technique of Heine for the detection of Cryptosporidium spp: a fast and simple screening technique. The open Parasitology Journal, 4, 1-4.

Prakash, S., Prabu, K., Palanivel, K. M., 2009. Prevalence of Cryptosporidiosis in dairy calves in Chennai. Tamilnadu J. Veterinary \& Animal Sciences, 5(2), 41-46.

Rahmeto Abebe, Abebe Wossene, Bersissa Kumsa, 2008. An epidemiological study of Cryptosporidium infection in dairy calves on selected dairy farms of central Ethiopia. Revue. Med. Vet., 159 (2), 107-111.

Santin, M., Trout, J.M., Xiao, L., Zhou, L., Greiner, E., Fayer, R., 2004. Prevalence and age related variation of Cryptosporidium species and genotypes in dairy calves. Veterinary Parasitology, 122, 103-117.

Taylor, M. A., Coop, R. L., Wall, L. R., 2000. Veterinary Parasitology. $3^{\text {rd }}$ ed. Blackwell Publishing, p. 627-628.

Trotz-Williams, L. A., Martin, S. W., Martin, D., Duffield, T., Leslie, K. E., Nydam, D. V., Jamieson F., Peregrine A. S., 2005. Multi-attribute evaluation of two simple tests for the detection of Cryptosporidium parvum in calf faeces. Veterinary Parasitology, 134,15-23. 
Urquhart, G. M., Armour, J., Duncan, J. L., Dunn, A. M., Jennings, F. W., 1987. Veterinary Parasitology, Blackwell science, London, UK. p. 22 6-227.

Wang, Y., Feng, Y., Cui, B., Jian, F., Ning, C., Wang, R., Zhang, L., Xiao, L., 2010. Cervine genotype is the major Cryptosporidium genotype

Walker, M., Leddy, K., Hagar, E., 2001. Effect of combined water potential and temperature stressors on Cryptosporidium parvum oocysts. Appl. Environ. Microbiol., 67, 5526-5529.

Xiao, L., Fayer, R., Ryan, U., Upton, S.J., 2004. Cryptosporidium taxonomy: recent advances and implications for public health. Clin. Microbiol. Rev., 17, 72-97. 